\title{
The paradox of our outcomes, and the use of qualitative methodology as a way to understand the realities of emerging countries
}

\author{
María Sandín Vázquez \\ Public Health and Medical-Social Sciences, Faculty of Medicine, Alcalá University, Alcalá de Henares, Spain \\ Email: maria.sandin@uah.es
}

Received 24 February 2012; revised 25 March 2012; accepted 9 April 2012

\begin{abstract}
It is a fact that global health indicators in vulnerable populations are not improving, despite all resources concentrated in this area. Therefore, as a teacher and researcher in an international doctorate in Public Health, I took advantage of the contact with health professionals from Colombia, Peru and Bolivia (they were all my students) to try to better understand which factors may be affecting this paradox from the perspective of the major actors and therefore through a qualitative methodology. The main conclusion is that the health goals for the target populations (emerging and developing countries) are not the same as the goals for the planners and administrators of public health budgets. So if we want to improve health outcomes, it is time to let talk the people involved, and to let the administrators listen.
\end{abstract}

Keywords: Global Health; Qualitative Research; Indigenous Populations

\section{INTRODUCTION}

As a professor in the Department of Public Health and Medical-Social Sciences (Alcalá University), I was invited to participate in an International Doctorate in Public Health at the Andina University of Sucre (Bolivia), held from 5 to 10 October 2009. I taught 40 hours training in qualitative methodology. At that time, I tried to understand the research interests of the 21 students (all professionals in the Public Health area) and for this reason, I finished my module with an exercise of design of a participatory action research in which these professionals chose the research topic according to the local needs in their daily work.

I will try to explain my vision as a researcher, teacher and especially as a person, based on the research objecttives that appeared in their exercise, which made me understand what are the problems found by health profes- sionals in their daily work in these emerging countries that impeded the efficacy of the goals and budgets designed according to the reality of these populations.

It is noteworthy that according to a 2005 report [1] indigenous population in Bolivia represents the majority of the population, reaching a 62\% (about 3.9 million people). In rural areas, $72 \%$ of the population speaks indigenous languages, compared with $36 \%$ in urban areas. With this review, I intend to contribute to the main subject of development cooperation, the paradox of our time, which despite all the activities and resources concentrated in these countries, the health improvement is not as spectacular as expected.

\section{METHODS}

Regarding the theoretical approach and methods, the present paper does not fit strictly in an ethnography [2,3], or participant observation [4,5]. I have conducted neither interviews [4] nor discussion groups [6,7]. I only analyze the work and the feedback from a group of health professionals attending a Ph.D. in Public Health. The analysis could be a mixture from both a phenomenological perspective $[8,9]$ (taking into account the subjective perspective of the participants in the doctorate) and a socioethnographic perspective $[10,11]$ (observing the way they work and their social characteristics). But it has several quality requirements (for "ensuring rigor" [12]) of this way of understanding the research problems from a qualitative standpoint [12-15]:

- With respect to internal validity (in qualitative research, called credibility), I have lived in Bolivia for 20 days with the health professionals and I have been working with them. They have shown their views as professionals through their research and exercise. In addition, I perform a data triangulation, including their written documents (the papers presented by the professionals) and a feedback to all participants or member check (with the co-evaluation that were performed by the 21 students to each one). That is, it is 
their reality, described by them, and evaluated by themselves, which claims to be adjusted to which they daily experience.

- With respect to external validity (in qualitative research, called transferability, despite the fact that the goal of this research is not to extrapolate to other populations), I worked for 5 years with similar population of students in Nicaragua. The basic problems exposed, are the same that we found in those years.

- For dependability and confirmability, another teacher, with whom I undertook the trip and who is also professor in my department, is the second vision that determines whether these interpretations are adapted to the reality of study.

\section{RESULTS}

Students of the international Ph.D. course are recognized professionals from the health area, working both as teachers and researchers in universities, as planners in hospitals and as managers in the Ministry of Health (Table 1). They know the multiple realities that coexist in their workplaces, existing large differences in the socioeconomic class (high, medium and low), in the geographic area (urban and rural areas) and above all cultural status (different ethnic groups with beliefs, habits and languages).

When they designed their work, the health themes were different (nutrition, reproductive health, occupational health, HIV (Table 2)), but with a common factor. Those who chose to work with people from most deprived areas (communities like San Isidro, Potosí, Chapinero or Huacareta) were aware of the great difficulty in carrying out programs with people who see health professionals outside their community. This people see professionals as outsiders that share neither aims, nor expected results in health (see Figure 1). From all the departments where these professionals work, effort and funds are intended to work with rural communities on issues identified by administrations of urban areas (obviously, other cultural and socioeconomic status). When these professionals come to deal with people (in most cases indigenous) are hardly accepted and, therefore, hardly listened.

They are aware that in order to make effective interventions, health problems should be identified by these marginal populations, because if it isn't, the indigenous population see the different programs as impositions from people outside their community, their culture and their interests. In many cases, my students noted that professionals should provide even both assistance and health promotion in a language unknown to them, with deep implications in achieving health outcomes. The understanding of life, health and disease of this population
Table 1. Health professionals characteristics.

\begin{tabular}{|c|c|c|c|}
\hline Profession & $\operatorname{Sex}^{\mathrm{a}}$ & Country & Institution \\
\hline Surgeon & M & Bolivia & Ministry of Health \\
\hline Surgeon & $\mathrm{F}$ & Colombia & University \\
\hline Surgeon & F & Perú & --- \\
\hline Odontologist & F & Bolivia & University \\
\hline Surgeon & M & Bolivia & University \\
\hline Nurse & $\mathrm{F}$ & Bolivia & Hospital \\
\hline Surgeon & $\mathrm{M}$ & Bolivia & Ministry of Health \\
\hline Surgeon & M & Bolivia & $\begin{array}{c}\text { Research Center, } \\
\text { Education and Services }\end{array}$ \\
\hline Surgeon & $\mathrm{F}$ & Colombia & University \\
\hline Surgeon & M & Bolivia & Ministry of Health \\
\hline Surgeon & M & Colombia & University \\
\hline Surgeon & M & Bolivia & --- \\
\hline Surgeon & M & Bolivia & University \\
\hline Nurse & M & Colombia & University \\
\hline Veterinary & $\mathrm{F}$ & Colombia & University \\
\hline Surgeon & M & Bolivia & --- \\
\hline Surgeon & M & Bolivia & Ministry of Health \\
\hline Surgeon & $\mathrm{F}$ & Bolivia & Ministry of Health \\
\hline Biologist & M & Colombia & Hospital \\
\hline Surgeon & F & Bolivia & University \\
\hline Surgeon & M & Colombia & $\begin{array}{l}\text { Ministry of Social } \\
\text { Protection }\end{array}$ \\
\hline Surgeon & $\mathrm{F}$ & Bolivia & Ministry of Health \\
\hline
\end{tabular}

${ }^{\mathrm{a}} \mathrm{M}$ : male; F: female.

Table 2. Research papers presented by health professionals in the qualitative research module.

Malnutrition reduction in children under 2 years of the community of San Isidro-Tarvita.

Lack of access to health services, vulnerable groups in the town of San Isidro UPZ Chapinero patios, Bogota, Colombia.

Voluntary diagnostic services, counselling and prevention of STIs, HIV-AIDS to the attention of the population, with emphasis on adolescents and high risk groups in the city of Sucre.

Mortality from accidents in the miners of Cerro Rico de Potosi.

Hepatitis B in the town of Huacareta. The health professionals vision. 


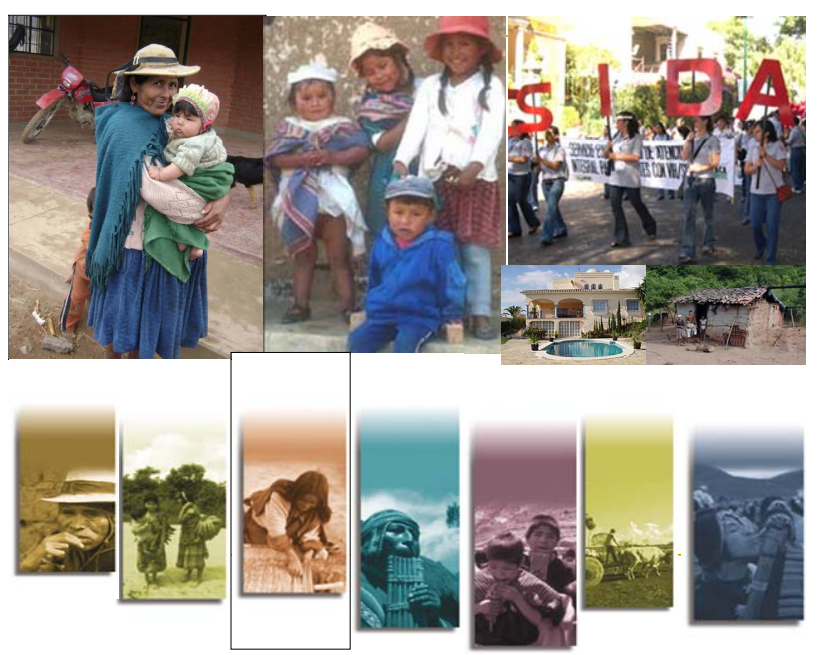

Figure 1. Photographs included in the papers submitted by health professionals in the qualitative research module, which reflect the different realities of their daily work.

is different. Therefore, in order to make improvements in their lives and their health, we must understand the way in which people interpret it and act accordingly.

\section{CONCLUSIONS}

If we do not strive to understand the different situations, involving different cultures and languages, is very difficult to allocate budgets and efforts to transform these realities in developing countries. It is necessary to understand and valuate them, to identify their problems and potentialities. As Ullin [16] says, "The fact that differences in the way that people interpret everyday situations (and, consequently, how they act on them) has profound implications for health research. If it is true that what people define as real is real in its consequences, then the applied research and the public health field must have the ability to discover multiple perspectives and understand their impact on decisions related to health".

To understand the current paradox (why there is no improvement in health outcomes after allocating efforts and budgets in these populations) it is necessary to remember the primary goal of Public Health, to provide health for the people, which we must set as a key objecttive assuming that the problems of these people are not the same problems that we think (as public health professionals). And it is necessary too to focus all our skills as researchers to understand how we can accomplish this difficult task, identify their problems, and propose strategies for addressing them. And qualitative research can be a helpful tool because, as Mercado says, "Qualitative Health Research is not limited to the use of qualitative data (as opposed to quantitative), or the use of a qualitative method or technique, whether for procurement, processing or data analysis. It is rather a field where knowledge and practices in different scientific traditions are brought together and try to do science around health, illness and care differently to the conventional model that, among other things, silenced the voices of too many actors [11].”

Perhaps the paradox of our health outcomes would be resolved by changing the targets, making their goals become the public health goals and not the goals that we define, and letting silenced people talk, because they have much to say.

\section{ACKNOWLEDGEMENTS}

Research funding for this study from the Spanish Cooperation Agency and Alcalá University is gratefully acknowledged. The assistance of students in facilitating this study is also gratefully acknowledged. The author further wish to thank Francisco Bolumar Montrull for creating the International Doctorate in Public Health at the Andina University of Sucre (Bolivia).

\section{REFERENCES}

[1] Hall, G. and Patrinos, H. (2005) Indigenous peoples, poverty and human development in Latin America: 1994-2004. http://go.worldbank.org/TXWP6Y78N0

[2] Malinowski, B. (1995) Argonauts of the Western Pacific: An account of native enterprise and adventure on the Archipelagoes of Melanesian New Guinea. Ediciones Peninsula, Barcelona.

[3] Amezcua, M. (2000) The fieldwork in health. One approach to participant observation. Index Confrontations (Grand), 30, 30-35.

[4] Taylor, S.J. and Bogdan, R. (1990) Introduction to qualitative research methods. Paidós, Buenos Aires.

[5] Kawulich, B.B. (2005) Participant observation as data collection method. Forum: Qualitative Social Research, 6 Art. 43.

[6] Gil Flores, J. (1993) Research methodology by discussion groups. Inter-University Teaching Yearbook, No. 10-11. 199-214.

[7] Ibanez, J. (1981) Uses and abuses topical of group techniques. Journal of the Spanish Association of Neuropsychiatry, 2, 16-36.

[8] Tesch, R. (1990) Qualitative research: Analysis types and software tools. Falmer, New York.

[9] Creswell, J.W. (1998) Qualitative inquiry and research design: Choosing among five traditions. Sage Publications, Inc., Thousand Oaks.

[10] Sparkes, A.C. (1992) The paradigms debate: An extended review and a celebration of difference. In: Sparkes, A.C. Ed., Research in Physical Education and Sport. Exploring Alternative Visions, The Falmer Press, Lewes, 9-60.

[11] Mercado Martínez, F.J., Villaseñor Farías, M. L. and Gómez, A. (2000) Current status of qualitative health research. Revista Universidad de Guadalajara. Número 17/Invierno Magazine 1999-2000. 
http://www.cge.udg.mx/revistaudg/rug17/entrada.html

[12] Morse, J.M., Barrett, M., Mayan, M., Olson, K. and Spiers, J. (2002) Verification strategies for establishing reliability and validity in qualitative research. International Journal of Qualitative Methods, 1, 1-19. http://www.ualberta.ca/ ijqm/

[13] Denzin, N.K. and Lincoln, Y.S. (1994) Handbook of qualitative research. Sage Publications, Inc., Thousand Oaks.

[14] Guba, E.G. and Lincoln, Y.S. (1994) Competing paradigms in qualitative research. In: Denzin, N.K. and Lin- coln, Y.S., Eds., Handbook of Qualitative Research, Sage Publications, Inc., Thousand Oaks,105-117.

[15] Calderón, C. (2002) Quality criteria in qualitative health research: Notes for a necessary debate. Revista Española de Salud Pública, 76, 473-482.

[16] Ulin, P.R. (2006) Applied public health research: Qualitative methods. Pan American Health Organization, Washington. 